\title{
PSYCHOPHYSICAL VALIDATION OF A DIGITAL METHOD TO ASSESS ILL-DEFINED VISUAL BOUNDARIES: AN EXAMPLE WITH FABRIC OPENNESS FACTOR
}

\section{ABSTRACT}

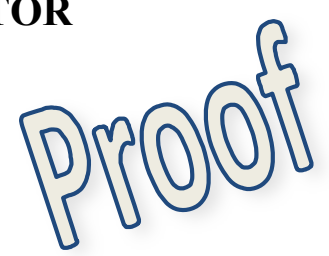

Fabric openness factor $(O F)$ is the fraction of the web area that is uncovered by yarns. $O F$ is a critical feature regarding the end-use performance of the fabric and should be accurately assessed. However, digital $O F$ estimates yielded by image binarization algorithms differ among them depending on the criteria used, mainly due to ill-defined boundaries, thus precluding a straightforward assessment of the actual fabric $O F$ value. Lacking any standard to compare actual $O F$ values with measured $O F$ values, we addressed the validation procedure of the digital assessment method from visual $O F$ estimates. $O F$ of 81 distinct fabric samples was evaluated from digital images by a panel of 18 observers using visual binarization technique. Following the psychophysical models of Fechner and Stevens, these visual estimates were correlated with digital estimates yielded by several binarization algorithms. Stevens' psychophysical model and an automatic binarization algorithm developed by us scored the highest correlation.

\section{PRACTICAL APPLICATIONS}

This work addresses the problems that arise at the moment of measuring the area of a region with illdefined boundaries without any standard to control the process of measurement. Similar problems are also found in important fields such as medical imaging. In these cases, there are usually different digital methods that give rise to estimates of the magnitude which mismatch among them. To solve these differences, a more common approach is to use estimates provided by a panel of observers and consider them to be objective, regardless of the bias between subjective responses and actual values. However, visual estimates do not show either accuracy (because they are psychophysical measures) or precision (due to the variability among observers). To overcome these difficulties, we propose a procedure to validate a digital method through visual estimates provided by a panel of observers, taking into account the psychophysical models of Fechner and Stevens. 


\section{INTRODUCTION}

The analysis of the relationship between instrumental and sensory measurements has been largely taken into consideration in the field of psychophysics and also applied to the study of textiles. The goal of the majority of these works is the estimation of the magnitude of human sensations based on instrumental measures, with examples of such studies found in the field of fabric hand (Zheng et al. 2004; Mazzuchetti et al. 2008; Rombaldoni et al. 2010; Jeguirim et al. 2012; Wang et al. 2012) and analysis of wet and clingy (Tang et al. 2015) and comfort (Kamalha et al. 2013) sensations, for instance. Our study also belongs to the sensory field but addresses the problem from a different angle. Instead of predicting subjective estimates of physical attributes, our aim is to use the subjective estimates of a panel of observers to validate an instrumental method of measurement that has no applicable standard.

Fabric openness factor $(O F)$ is the fraction of the web area uncovered by yarns (Fig. 1). $O F$ is a critical feature regarding the end-use performance that has to be taken into consideration in the fields of protection (Webster et al. 2009; Gabrijelčič et al. 2009; Dimitrovski et al. 2010; Gotipamul et al. 2014), end-use performance (Teli et al. 2008; Akgun et al. 2012), thermo-physiological comfort (Özçelik et al. 2007; Lee and Obendorf 2012; Kumar and Mitra 2013) and fabric hand (Naebe et al. 2013). In the specialized literature, it is more usual to deal with $O F$ complementary, the cover factor (i.e. the fraction of the web area covered by yarns) (Marks et al. 1993). However, the use of either cover factor or $O F$ is completely equivalent since their sum is the unit. The classical way to estimate $O F$ is through several well-known theoretical formulae that depend on fabric structural parameters, such as its yarn linear densities, yarns per unit length and width or type of weave. Nevertheless, all these theoretical approaches lead to $O F$ estimates that mismatch among them and do not take into account fabric's reality, with the possible bias from the original design (Galcerán 1961).

FIG. 1

At the end of the last century, digital image processing in textiles opened a window of opportunity to measure $O F$ objectively (Behera 2004). Several works attempted to make automatic estimations of $O F$ by means of a fabric digital image but all the proposed methods depended on parameters that had to be set by subjective criteria at some point (Castellar et al.1997; Mikolajczyk 2001; Kang et al. 
2001; Cardamone et al. 2002; Abou-Ilana et al. 2003). Moreover, the lack of any standard to control a process of $O F$ measurement among researchers and manufacturers has considerably hindered both the comparison of the different methods and the direct validation of results.

In the context of image processing, the automatic technique most widely used in the estimation of fabrics $O F$ is the global binarization of a gray level fabric digital image. However, due to the fact that the digital images usually reveal fuzzy boundaries resulting in $O F$ being an ill-defined magnitude, automatic binarization algorithms do not always lead to $O F$ estimates showing a good match among them (Tàpias et al. 2010). With the aim to clarify this uncertainty, we relied on the visual assessments issued by a panel of observers on the same digital images, because observers can discern better between yarns and holes than automatic algorithms. Nevertheless, our initial hypothesis is that subjective estimates cannot be considered objective because they do not show either accuracy (they are psychophysical measures) or precision (due to the variability among observers) and thus cannot be considered to be the true $O F$ value. Regarding the first step of our hypothesis, the relationship between the magnitude of sensation and the stimulus intensity has been described by Fechner's logarithmic model (Fechner 1860) and Stevens'power law (Stevens 1986). Both psychophysical models have also been taken into consideration in recent works (Rombaldoni et al. 2010; Billock and Tsou 2011; Adler et al. 2014). Referring to the second step of our hypothesis, to account for the variability among observers, we use the mean of the estimations given by a panel of observers for a set of distinct fabric sample images. This set of mean $O F$ values is taken as the set of magnitudes of sensation to be correlated with any set of digital $O F$ estimates through psychophysical models. The highest correlation will lead both to the choice of the psychophysical model and to the final automatic $O F$ algorithm in order to establish the foundation for a proper digital $O F$ estimation method. Fig. 2 shows the block diagram of the process.

FIG. 2

\section{MATERIALS AND METHODS}

\section{Fabric samples}

The study included a set of 81 different plain fabric samples, resulting from the combination of four fabric features: type of fiber, warp linear density, weft linear density and yarns per unit length, each 
one investigated at three different levels. Yarns per unit width were kept constant. Fabric structural parameters of these fabric samples are presented in Table 1.

\section{TABLE 1}

\section{Digital images of fabrics}

Fabric digital images were captured with a microscope and preprocessed following our previous works (Tàpias et al. 2010, 2011). Fig. 3(a) shows a gray level digital image to be processed. It should be pointed out that the difficulties in $O F$ measurements from gray level fabric digital images come from the fact that the boundaries separating yarn and hole are fuzzy, making their localization ambiguous. Fig. 3(b) shows a plot profile of the red segment in Fig. 3(a) just on the border between yarn and hole, with a visible border fuzziness of about 30 pixels. This border fuzziness is the reason behind the differences among $O F$ estimates obtained using different automatic binarization methods; it is also the cause of discrepancies among visual $O F$ judgments.

FIG. 3

\section{Psychophysical $O F$ assessment}

Eighteen observers took part in the experiment. Twelve of them belong to the Applied Optics and Image Processing Research Group of the Optics and Optometry Department of the Universitat Politècnica de Catalunya. This research group works on vision systems and image analysis applied to industrial production and inspection, particularly in the textile area. The rest of the observers are members of the Department used to performing computer image analysis tasks. There were eleven women and seven men aged forty on average. All the participants in the study had normal or corrected to normal visual acuity for the viewing distance of the experiment. They also had normal color vision. The observers didn't have prior knowledge of psychophysical experiments like the one in the study and were given instructions about how to proceed. They could first try the mechanics of the psychophysical method on a trial image before proceeding to the actual measurements. The measurement took place in three separate days (one for each type of fiber) in order to avoid visual 
fatigue. In each session, the observers had to evaluate a series of 27 fabric samples images, with a total of 81 images by the end of the experiment.

Interactive visual binarization was performed with the help of a personal computer $(P C)$. Two identical gray scale images of a sample were presented to the observer on a $P C$ screen that had the controls fixed during the whole experiment and for all the observers (Fig. 4). The left side image remained fixed while the observer slid the cursor in order to select a threshold value. The pixels with intensities higher than the selected threshold changed their color to magenta in the right side image for a better visualization of the binarization result. The observer set the threshold value by seeking the best match between the bright pixels corresponding to the fabric holes in the left side image and the magenta pixels in the right side image. To conclude, $O F$ was straightforwardly obtained as the ratio of magenta pixels to the total number of pixels of the right side image.

FIG. 4

As we have mentioned earlier (Fig. 3), in the gray level digital fabric images the boundaries separating yarns and holes are neither sharp nor abrupt. They show a smooth gradient between high gray level (holes) and low gray level (yarns). Therefore, each observer sets the limit between yarn and hole in a different subjective position. The holes in the digital fabric image display a pattern of areas with fuzzy boundaries. The visual task carried out by the panel of observers consisted of subjective matching of a non-connected surface area with crisp boundaries with a non-connected surface area with fuzzy boundaries. The intention was to assess the area of the surface with fuzzy boundaries, by means of the area of the matching surface with crisp boundaries (image segmented by the observer). Therein lay the difficulty of the experiment and, at the same time, the increment of variability among observers.

Once the observer chose the optimal threshold, $O F$ was computed as

$$
O F=\frac{\text { number of pixels with gray level }>\text { threshold }}{\text { number of pixels in the image }} .
$$




\section{Performing automatic $O F$ estimates}

In order to determine the thresholds that led to the digital $O F$ estimations we analyzed four classical global binarization algorithms (Gaussian modeling (GM), Kittler-Illingworth (K-I), Otsu and Kmeans) (Sezgin and Sankur 2004) in addition to the one proposed in our previous works (Tàpias et al. 2010, 2011), the Minimum Sum of Squared Residuals (MSSQ). These five binarization algorithms were applied to the digital images of the 81 fabric samples. All these algorithms are based on the segmentation of the histogram of the gray level fabric digital image. For the threshold obtained, they classify the pixels of the image depending on their gray level: pixels with gray level lower or equal to the threshold belong to the yarns class and pixels with gray level higher than the threshold belong to the holes class. $O F$ estimation is derived from the previous classification through eq. (1).

\section{Psychophysical models relating magnitude of perception and stimulus intensity}

Although the psychophysical model of Stevens is the one most commonly used to describe perceived responses in visual tasks (Stevens 1961; Stevens 1999), we also wanted to analyze experimental data behavior through Fechner model. Therefore, the correlation of the mean visual $O F$ estimates (assessed by the panel of observers) with the digital $O F$ estimates (computed using the five automatic binarization algorithms) was obtained using the following mathematical expressions:

$$
\begin{gathered}
S=a \cdot \ln I+k \quad(\text { Fechner Law }), \\
S=\beta \cdot I^{\alpha} \quad(\text { Stevens Law }),
\end{gathered}
$$

where $S$ is the perceived magnitude of sensation evoked by a physical stimulus of magnitude $I$. In the present case, $S$ refers to the visually estimated $O F$ value, $I$ is the digital $O F$ estimated through the 
binarization algorithm and $a, k, \beta$ are constants that depend on the experiment carried out. Thus, there were five sets of 81 digital $O F$ estimates (computed using the five digital binarization algorithms) and two mathematical models to correlate those digital data with the visual ones. Therefore, the fitting of these five sets of digital $O F$ estimations with the visual $O F$ estimations that take into account the two psychophysical models (Fechner and Stevens) leads to the total amount of ten correlations. Following our initial hypothesis, the correlation with the highest determination coefficient would indicate the most suitable binarization algorithm to compute digital $O F$ estimates.

\section{RESULTS AND DISCUSSION}

\section{Visual $O F$ estimates}

Fig. 5 is a gray-scale matrix representation, for each type of fiber, of the visual $O F$ judgments made by the panel of 18 observers on the 81 fabric samples. In every matrix fabric samples are classified horizontally from the lower to the higher $O F$ value average (located at the bottom but next to the matrix). A ten gray-level scale from the lower $O F$ (white) to the highest $O F$ (black) is also included in order to make the numerical interpretation of the matrix elements easier. The observers are vertically classified, labeled following the alphabet. Hence, every matrix row corresponds to the $O F$ judgments of an observer for all the fabric samples whilst every matrix column contains the $O F$ judgments of the 18 observers for the same fabric sample. This type of data presentation reveals the amount of variability among different observers for the visual $O F$ judgments, and confirms our initial hypothesis about the imprecision of psychophysical $O F$ estimations due to both the inherent subjective nature of the measure and to the border fuzziness.

Fig. 5 also reveals the existence of significantly different observers' behaviors. Observers $A$ or $G$ tended to overestimate $O F$ for all the fabric samples while the performance of observer $E$ is the opposite and assigned systematically low $O F$ values.

FIG. 5

Another characteristic of this variability is reflected in Fig. 6 which shows the dependence of the standard deviation on the value of the visual $O F$ magnitude, for each type of fiber. As the $O F$ increases, so do the discrepancies among the observers. 
FIG. 6

Table 2 shows Pearson correlation coefficients (bottom) and rank correlation coefficients (top) between pairs of observers. In general, high coefficient values were obtained. This implies that estimates provided by observers with different profiles are consistent with each other, despite being different. Low $O F$ values given by an observer correspond to low $O F$ values given by another observer, with the same being true for the high ones. From this table it can be seen that observers $O$ and $P$ are those who have the lowest correlation coefficients (both Pearson and rank correlation coefficients). This behavior different from the rest of observers indicates that observers $O$ and $P$ cannot see the difference between fabric samples in the same way as other observers do. However, their estimations were also included in the present work.

\section{TABLE 2}

\section{Psychophysical correlations of digital $O F$ estimates}

Fig. 7 shows the scatterplots of the averaged $O F_{\text {visual }}$ of all the observers vs. the digital $O F$ estimates computed using the five automatic binarization algorithms $\left(O F_{\text {algorithm }}\right)$ : Fig. 7(a), Gaussian modeling, Fig. 7(b), K-means, Fig. 7(c), Otsu, Fig. 7(d), Kittler-Illingworth (K-I) and Fig. 7(e), $M S S Q$. Each scatterplot contains logarithmic and nonlinear potential fittings which correspond to Fechner and Stevens' models, respectively. Nonlinear fitting was obtained through Mardquard method (Statgraphics Plus 5.1). At first glance, we see that with Gaussian modeling (Fig. 7(a)), Kmeans (Fig. 7(b)), and Otsu (Fig. 7(c)) automatic binarization algorithms, psychophysical models led to inconsistent $O F$ estimations because the fitted curves do not show the expected monotonous growth. Therefore, we discarded these algorithms in our computation of the digital $O F$ values. In contrast, the curves fitted by Kittler-Illingworth (Fig. 7(d)) and MSSQ (Fig. 7(e)) algorithms behave as expected. In these two last cases, we compared the determination coefficients obtained with each psychophysical model in order to choose the psychophysical model showing the best relationship between the stimulus magnitude and the sensation magnitude. In both cases, Stevens' psychophysical model shows the highest determination coefficient, as can be seen in Fig. 7(d) and 7(e) and in table 3. 


\section{TABLE 3}

The similarity between the determination coefficients of Kittler-Illingworth and MSSQ methods obtained with Stevens' psychophysical model fitting allows us to state that both algorithms are almost equally valid to be taken into account to digitally estimate $O F$, although $M S S Q$ algorithm provides a correlation slightly higher than Kittler-Illingworth's.

\section{FIGURE 7}

With the aim to compare our digital $O F$ estimations with those obtained by Stevens in the visual estimation of the magnitude of a squared area, we should consider the linear form of his model since it is the one that he fitted,

$$
\log S=\alpha \log I+\log \beta
$$

where the slope of the line, $\alpha$, is the exponent of Stevens' law (eq. (3)). Thus, fitting a linear regression to the logarithm of the mean values of visual $O F$ estimates and the logarithm of digital values computed through Kittler-Illingworth and $M S S Q$ algorithms, the value of Stevens' exponent has slightly decreased in comparison with the one obtained with the nonlinear fitting. Table 4 shows exponent and determination coefficient obtained by fitting Stevens' linear regression model to logarithmic transformed data. The exponent now is closer to 0.7, as predicted by Stevens (Stevens 1961; Stevens 1999) and assumed to be true in a recent work (Li et al. 2010), even though the shape of the area evaluated was circular instead of squared. This confirms, as Stevens said and Moskowitz et al. (1981), that Stevens' exponent “is reliable and can be reproduced from one laboratory to another" and that "it is a characteristic of each sensory continuum".

\section{TABLE 4}

Notice that Stevens' exponents, $\alpha$, obtained with the nonlinear and linear forms of Stevens' model differ slightly. This is because residuals corresponding to both fits are different and their minimization is achieved with different values of $\alpha$ and $\beta$ parameters. However, in order to compare our experiment with that of Stevens, $\alpha$ values to be considered are those in table 4 , derived from the linear form of Stevens' law. 


\section{CONCLUSIONS}

In this work we addressed the problem of making digital estimations of the area of regions with fuzzy boundaries without any standard procedure to control the process of measurement. We analyzed a real problem - the digital determination of the fabric $O F$, and proposed a method to solve it. A priori, there are several valid digital methods to measure fabric $O F$ with no prevalence of one over the others. However, these digital methods give rise to estimations that mismatch among them and, consequently, this inconsistency has to be analyzed. We assumed that these differences arise from the performance of the binarization methods at the boundaries of the regions whose area has to be assessed. Lacking any standard to validate the results provided by those binarization methods, we turned to psychophysical models to find the one that would deliver the best match with visual assessments. Psychophysical models relate the magnitude of the stimulus with the magnitude of the sensation. Therefore, we obtained the mean $O F$ of visual estimates given by a panel of 18 observers on 81 distinct image fabric samples. Then we took into account the relationship between the stimulus magnitude (the digital $O F$ values) and the magnitude of the sensation (the visual $O F$ estimations). This relationship is modeled by the two psychophysical approaches of Fechner and Stevens. Looking at the results, we concluded that three of the digital methods used (Gaussian modeling, K-means and Otsu) were not consistent with the visual $O F$ and hence rejected them as valid digital $O F$ estimations.

The two remaining digital $O F$ estimation methods (Kittler-Illingworth and MSSQ) showed higher correlations with Stevens' approach than with Fechner's. This probably means that Stevens' model describes more accurately the behavior of subjective sensation in this kind of visual tasks than Fechner's.

We fitted the Stevens' potential model with nonlinear regression techniques to raw data. We observed few differences in the determination coefficients of Kittler-Illingworth and MSSQ binarization algorithms using this model $\left(\mathrm{R}^{2}=0.9089\right.$ for Kittler-Illingworth and $\mathrm{R}^{2}=0.9298$ for $M S S Q$ algorithms). Few differences can be noticed in $\alpha$ exponents ( $\alpha=0.7702$ for Kittler-Illingworth and $\alpha=0.7990$ for $M S S Q$ algorithms).

Moreover, we fitted Stevens' linear model to the logarithmically transformed data as well, as did Stevens. This fit resulted in greater differences in the determination coefficients between KittlerIllingworth and $M S S Q$ algorithms $\left(\mathrm{R}^{2}=0.8451\right.$ for Kittler-Illingworth and $\mathrm{R}^{2}=0.9303$ for $M S S Q$ 
algorithms). Despite this, the linear fit yielded Stevens' exponent values close to 0.7 ( $\alpha=0.7165$ for Kittler-Illingworth and $\alpha=0.7350$ for $M S S Q$ algorithms), very similar to the value obtained by Stevens in his original work of visual squared area estimation. This fact reinforces the analogy between our experiment (estimation of the surface of a pattern of areas) and Stevens' task.

The method has been tested on plain fabric samples with $O F$ ranging from 0 up to 0.174 . Presumably, the method should work for single layer fabric samples weaved differently from plain weave as long as their thickness does not exceed the depth of field of the image capturing system.

To sum up, Stevens' power law combined with $M S S Q$ binarization algorithm provided the best fit between digital and visual $O F$ estimates of the analyzed fabric sample images, which validates this set of digital $O F$ values as the one most consistent with the visual $O F$ estimates obtained by the observers.

\section{REFERENCES}

ABOU-ILANA, M.M., YOUSSEF, S.S., PASTORE, C.C., and GOWAYED, Y.Y. 2003. Assessing structural changes in knits during processing. Text. Res. J. 73(6), 535-540.

ADLER, M., MAYO, A., and ALON, U. Logarithmic and power law input-output relations in sensory systems with fold-change detection. PLoS Comput. Biol. 2014; 10(8), e1003781. doi:10.1371/journal.pcbi.1003781.

AKGUN, M.M., BECERIR, B.B., and ALPAY, H.R. 2012. Investigation of color differences of cotton, polyester and polyester/cotton blend fabrics after wash fastness tests according to their fabric cover factors. Colourage 59(2), 33-41.

BEHERA, B.K. 2004 Image-processing in textiles, Text. Prog. 35(2), 1-193.

BILLOCK, V.A. and TSOU, B. H. 2011. To honor Fechner and obey Stevens: relationships between psychophysical and neural nonlinearities, Psychol. Bull. 137(1), 1-18.

CARDAMONE, J.M., DAMERT, W.C., PHILliPS, J.C., AND MARMER, W.N. 2002. Digital image analysis for fabric assessment, Text. Res. J. 72(10), 906-916.

CASTELlAR, M.D., MANICH, A.M., CARVALHO, J., and BARELLA, A. 1997. An application of the image analysis to the woven fabric cover factor determination, in: "Niches in the World of 
Textiles: the 77th World Conference of the Textile Institute, Tampere," 2, 56-72, The Textile Institute, Manchester, UK.

DIMITROVSKI, K., SLUGA, F., and URBAS, R. 2010. Evaluation of the structure of monofilament PET woven fabrics and their UV protection properties. Text. Res. J. 80(11), 1027-1037.

FECHNER, G.T. 1860. Elemente der Psychophysik Vol. 2. Leipzig: Breitkopf \& Hartel.

GABRIJELCIČ, H., URBAS, R., SLUGA, F., and DIMITROVSKI, K. 2009. Influence of fabric constructional parameters and thread colour on UV radiation protection. Fibres \& Text. East. Eur. $72(1), 46-54$.

GALCERÁN, V. 1961. Tecnología del tejido. Vol. 2: Análisis de tejidos y técnica de su fabricación, (Fabrics Technology. Vol. 2: Fabrics Analysis and Manufacturing Technique), 2nd ed., ETSIIT, Terrassa, Spain.

GOTIPAMUL, R.L., DANDGOLE, P.B., DUDAGI, I.B., PRASAD, J., SURWASE, S.S., YUVRAJ, T. and DEORI, R. 2014. Effect of cover factor and weave factor on flammability characteristics of $100 \%$ cotton fabric. Melliand Int. 20(1), 35-37.

KAMALHA, E., ZENG, Y., MWASIAGI, J.I. and KYATUHEIRE, S. 2013, The comfort dimension; a review of perception in clothing. J. Sens. Stud. 28, 423-444

KANG, T.J., CHOI, S.H., KIM, S.M., and OH, K.W. 2001. Automatic structure analysis and objective evaluation of woven fabric using image analysis, Text. Res. J. 71(3), 261-270.

KUMAR De, S., and MITRA, A. 2013. A study of some mechanical properties of eri fabric and comparative study with wool fabric. Man-Made Text. India, 41(5), 162-166.

JEGUIRIM, S. E. G., ADOLPHE, D. C., SAHNOUN, M., DOUIB, A. B., SCHACHER, L. M., and CHEIKHROUHOU, M. 2012. Intelligent Techniques for Modeling the Relationships between Sensory Attributes and Instrumental Measurements of Knitted Fabrics. J. Eng. Fiber. Fabr., 7(3), $88-96$.

LEE, S., and OBENDORF, S. 2012. Statistical modeling of water vapor transport through woven fabrics. Text. Res. J. 82(3), 211-219. 
LI, J., MARTENS, J.B. and VAN WIJK, J.W. 2010. A model of symbol size discrimination in scatterplots. Proceedings of the 28th ACM Conference on Human Factors in Computing Systems (CHI 2010), Atlanta GA, USA, 2553-2562. ACM.

MARKS, R., LAWTON, P.J., and HOLME, D.A. 1993, An introduction to textiles. Vol. III Fabrics, Chap. 2, p. 38-39, School of Textile Studies, Bolton Institute of Higher Education, Bolton, UK.

MAZZUCHETTI G., DEMICHELIS R., SONGIA M. B. and ROMBALDONI F. 2008. Objective Measurement of Tactile Sensitivity Related to a Feeling of Softness and Warmth. Fibres Text. East. Eur. 16(4(69)), 67-71.

MIKOLAJCZYK, Z. 2001. Analysis of warp knitted fabrics' relative cover with the use of computer technique of image processing. Fibres Text. East. Eur. 9, 26-29.

MOSKOWITZ, H. R. 1981. Relating subjective and instrumental measures a psychophysical overview. J. Food Quality, 4(1), 15-33.

NAEBE, M., LUTZ, V., MCGREGOR, B.A., TESTER, D. and WANG, X. 2013. Predicting comfort properties of knitted fabrics by assessing yarns with the Wool ComfortMeter. J. Text. I. 104(6), $628-633$.

ÖZÇELIK, G., ÇAY, A., and KIRTAY, E. 2007. A study of the thermal properties of textured knitted fabrics. Fibres Text. East. Eur. 15(1), 55-58.

ROMBALDONI, F., DEMICHELIS, R. and MAZZUCHETTI, G. 2010. Prediction of human psychophysical perception of fabric crispness and coolness hand from rapidly measurable lowstress mechanical and thermal parameters. J. Sens. Stud. 25, 899-916.

STEVENS S. S. 1961. To honor Fechner and repeal his law. Science 133, 80-86.

SEZGIN, M., and SANKUR, B. 2004. Survey over image thresholding techniques and quantitative performance evaluation, J. Electronic Imaging 13(1), 146-168.

STEVENS J.C. and MARKS L.E. 1999. Stevens power law in vision: exponents, intercepts, and thresholds, in Fechner Day 99: Proceeding of the Fifteenth Annual Meeting of the International Society for Psychophysics, P. Killeen and W. Uttal, eds. (ISP, 1999), p. 82-87. 
STEVENS, S.S. 1986. Psychophysics. Introduction to its perceptual, neural and social prospects. Chap. 1, p. 13-1, reprint Transaction Publishers, New Brunswick (New Jersey).

TANG, K. P. M., KAN, C. W. and FAN, J. T. 2015. Psychophysical Measurement of Wet and Clingy Sensation of Fabrics by the Volar Forearm Test. J. Sens. Stud. 30(4), 329-347.

TÀPIAS, M., ESCOFET, J., RALLÓ, M., ALGABA, I., and RIVA, A. 2010. Objective measure of woven fabric's cover factor by image processing. Text. Res. J. 80(1), 35-44.

TÀPIAS, M., RALLÓ, M., and ESCOFET, J. 2011. Automatic measurements of partial cover factors and yarn diameters in fabrics using image processing. Text. Res. J., 81(2), 173-186.

TELI, M.D., KHARE, A.R., and CHAKRABARTI, R. 2008. Dependence of yarn and fabric strength on the structural parameters. Autex Res. J. 8(3), 63-67.

WANG, H., MAHAR, T. J. and HALL, R. 2012. Prediction of the handle characteristics of lightweight next-to-skin knitted fabrics using a fabric extraction technique. J. Text. I. 103(7), 691-697.

WEBSTER, J., FUJIYAMA, T., YAHATA, D., and YOKOI, D. 2009. Woven fabric for air bags, air bags and process for production of the woven fabric. Extracts from European Patent Applications, Part 1B: Primary Industry, Fixed Constructions, Mining 25(14), 1491.

ZAOUALI, R., MSAHLI, S., EL ABED, B., \& SAKLI, F. 2007. Objective evaluation of multidirectional fabric wrinkling using image analysis. J. Text. I., 98(5), 443-451.

ZENG, X., KOEHL, L., SANOUN, M., BUENO, M. A. and RENNER, M. 2004. Integration of human knowledge and measured data for optimization of fabric hand. Int. J. Gen. Syst, 33(2-3), 243-258.

\section{FUNDING}

This work was supported by the Ministerio de Economía y Competitividad (Project DPI2013-43220$\mathrm{R})$. 


\begin{tabular}{|l|c|c|c|c|}
\hline \multirow{2}{*}{ FIBER } & \multicolumn{2}{|c|}{ Yarn linear density (tex) } & \multicolumn{2}{c|}{ (Yarns/cm) } \\
\cline { 2 - 5 } & Warp & Weft & Yarns per unit width & Yarns per unit length \\
\hline Cotton & $10,20,25$ & $10,20,25$ & 38 & $23,25,27$ \\
\hline Modal & $10,20,25$ & $10,20,25$ & 38 & $23,25,27$ \\
\hline Modal Sun & $10,20,29$ & $10,20,29$ & 38 & $23,25,27$ \\
\hline
\end{tabular}

TABLE 1

\begin{tabular}{|c|c|c|c|c|c|c|c|c|c|c|c|c|c|c|c|c|c|c|}
\hline & A & B & C & D & $E$ & $F$ & G & H & I & $\mathbf{J}$ & K & $L$ & M & $\mathbf{N}$ & 0 & $\mathbf{P}$ & $\mathbf{Q}$ & $\mathbf{R}$ \\
\hline A & & 893 & 0,808 & 0,890 & 0,893 & 0,871 & 0,742 & 0,871 & 0,823 & 0,837 & 0,901 & 0,855 & 0,888 & 0,886 & 0,619 & 0,615 & 0,803 & 0,865 \\
\hline B & 389 & & ,904 & 959 & 0,975 & 0,914 & 0,756 & 938 & 891 & 0,890 & 0,968 & 0,906 &, 965 & 0,906 & 629 & 0,693 &, 809 &, 944 \\
\hline C & 02 & 899 & & 875 & 879 & 361 & 0,735 & 364 & 806 & 843 & 1 & 833 & 900 & 27 & 32 & 31 & 83 & 55 \\
\hline D & 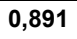 & 969 & 869 & & 965 & 0,914 & 0,783 & 0,921 & 0,867 & 0,870 & 0,961 & 0,924 & 0,938 & 0,925 & 0,604 & 0,710 & 0,798 & 0,936 \\
\hline$E$ & 863 & 945 & 0,849 & 0,955 & & 0,922 & 0,758 & 0,926 & 0,883 & 0,871 & 0,963 & 0,931 & 0,951 & 0,908 & 0,631 & 0,704 & 0,845 & 0,942 \\
\hline$F$ & 373 & 901 & 0,825 & 905 & 0,870 & & 0,705 & 0,888 & 0,876 & 0,895 & 0,910 & 0,850 & 0,910 & 0,882 & 0,672 & 0,629 & 0,795 & 0,907 \\
\hline G & 0,718 & 442 & 723 & 776 & 791 & 0,674 & & 0,746 & 691 & 650 & 0,777 & 0,7 & 772 & 31 & 6 & 7 & 330 & 20 \\
\hline $\mathrm{H}$ & 359 & 32 & 868 & 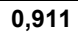 & 860 & 865 & 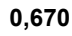 & & 0,861 & 0,880 & 0,938 & 0,852 & 0,934 & 0,895 & 0,6 & 0 & 66 & 0,912 \\
\hline$I$ & 834 & 870 & ,787 & 853 & 0,834 & 0,864 & 0,636 & 847 & & 0,832 & 0,886 & 0,820 & 0,869 & 0,857 & 0,624 & 0,579 & 0,743 & 0,874 \\
\hline $\mathbf{J}$ & 334 & 857 & 0,804 & 38 & 0,791 & 0,862 & 0 & 858 & 0,789 & & 0,881 & 0,8 & 0,898 & 11 & 9 & 12 & 0,755 & 0,855 \\
\hline K & 0,904 & 971 & 869 & 961 & 921 & 909 & $14 T$ & 930 & 875 & 0,868 & & 0,902 & 0,945 & 0,934 & 0,635 & 0,673 & 0,799 & 0,936 \\
\hline $\mathbf{L}$ & 366 & 922 & 833 & 925 & 934 & 0,853 & ,707 & 0,869 & 0,821 & 0,828 & 0,909 & & 0,892 & 0,868 & 0,559 & 0,719 & 0,828 & 0,856 \\
\hline M & 0,886 & 0,969 & 0,911 & 0,945 & 0,920 & 0,894 & 0,744 & 0,929 & 0,857 & 0,872 & 0,950 & 0,895 & & 0,887 & 0,653 & 0,684 & 0,778 & 0,920 \\
\hline $\mathbf{N}$ & 0,883 & 0,903 & 0,806 & 0,906 & 0,863 & 0,875 & 0,700 & 0,866 & 0,858 & 0,835 & 0,936 & 0,877 & 0,875 & & 0,604 & 0,655 & 0,761 & 0,876 \\
\hline 0 & 0,566 & 582 & 540 & 560 & 543 & 0,603 & 385 & 548 & 511 & 655 & 0,596 & 0,524 & ,601 & 0,548 & & 0,398 & 0,562 & 0,633 \\
\hline $\mathbf{P}$ & 0,538 & 0,603 & 0,624 & 0,610 & 0,630 & 0,512 & 0,499 & 0,565 & 0,492 & 0,455 & 0,560 & 0,616 & 0,604 & 0,532 & 0,290 & & 0,531 & 0,660 \\
\hline $\mathbf{Q}$ & 760 & 777 & 0,637 & 0,755 & 0,753 & 0,766 & 0,541 & 0,737 & 0,698 & 0,766 & 0,763 & 0,759 & 0,764 & 0,704 & 0,496 & 0,409 & & 0,776 \\
\hline $\mathbf{R}$ & 0,872 & ,936 & 842 & 937 & 0,887 & 0,895 & 0,683 & 0,903 & 0,852 & 0,853 & 0,935 & 0,882 & 0,919 & 0,889 & 0,579 & 0,541 & 0,741 & \\
\hline
\end{tabular}

TABLE 2 


\begin{tabular}{|l|c|c|}
\cline { 2 - 3 } \multicolumn{1}{c|}{} & \multicolumn{2}{c|}{ Determination coefficient $\left.\mathbf{( R}^{2}\right)$} \\
\cline { 2 - 3 } \multicolumn{1}{c|}{} & Stevens approx. & Fechner approx. \\
\hline Kittler-Illingworth & 0.9089 & 0.7629 \\
\hline MSSQ & 0.9298 & 0.7747 \\
\hline
\end{tabular}

TABLE 3

\begin{tabular}{|l|c|c|}
\cline { 2 - 3 } \multicolumn{1}{c|}{} & $\boldsymbol{\alpha}$ & $\mathbf{R}^{\mathbf{2}}$ \\
\hline Kittler-Illingworth & 0.7165 & 0.8451 \\
\hline MSSQ & 0.735 & 0.9303 \\
\hline
\end{tabular}

TABLE 4 


\section{FIGURE CAPTIONS}

FIG. 1. A-FABRIC IMAGE; B- FABRIC OPENNESS IMAGE.

FIG. 2. SCHEMATIC DIAGRAM OF THE PROCEDURE.

FIG. 3. A- ENLARGED DETAIL OF A FABRIC IMAGE SHOWING IN RED THE PLACE WHERE THE THREAD-HOLE BOUNDARY PROFILE IS DETERMINED, B- INTENSITY PLOT OF THE PROFILE INDICATED IN IMAGE A.

FIG. 4. SCREEN PRESENTED TO THE OBSERVERS: FIXED IMAGE (LEFT) AND VISUALLY-THRESHOLDED IMAGE (RIGHT).

FIG. 5. GRAY-SCALE MATRIX REPRESENTATION OF THE VISUAL OF ASSESSED BY THE 18 OBSERVERS ON THE 81 FABRICS.

FIG. 6. PLOT OF THE STANDARD DEVIATION OF VISUAL OF ESTIMATES VS. THE VISUAL $O F$ MEAN VALUE.

FIG. 7. PLOTS OF OBSERVERS' MEAN $\left(\right.$ OF $\left._{\text {VISUAL }}\right)$ VS. OF $F_{\text {ALGORITHM: A-GAUSSIAN }}$ MODELING, B-K-MEANS, C-OTSU, D-KITTLER-ILLINGWORTH AND E-MSSQ METHODS IN ACCORDANCE WITH FECHNER'S (gray) AND STEVENS' (black) PSYCHOPHYSICAL METHODS.

\section{TABLE CAPTIONS}

TABLE 1. STRUCTURAL PARAMETERS OF THE FABRIC SAMPLES.

TABLE 2. PEARSON CORRELATION COEFICIENTS (BOTTOM) AND RANK CORRELATION COEFICIENTS (TOP) OF SUBJECTIVE ESTIMATIONS BETWEEN PAIRS OF OBSERVERS.

TABLE 3. DETERMINATION COEFFICIENTS OBTAINED BY NONLINEAR REGRESSION KITTLER-ILLINGWORTH AND MSSQ OF VALUES TO VISUAL $O F$ VALUES. LEFT COLUMN, STEVENS APPROXIMATION. RIGHT COLUMN, FECHNER APPROXIMATION.

TABLE 4. EXPONENT AND DETERMINATION COEFFICIENT OBTAINED BY FITTING STEVENS’ LINEAR REGRESION MODEL TO LOGARITHMIC TRANSFORMED DATA. 